\title{
Characterization of monoclonal antibodies to bovine enteric coronavirus and antigenic variability among Quebec isolates
}

\author{
Brief Report \\ L. Michaud and S. Dea \\ Centre de Recherche en Virologie, Institut Armand-Frappier, Université du Québec, \\ Laval-des-Rapides, Québec, Canada \\ Accepted February 6, 1993
}

Summary.Twenty monoclonal antibodies (MAbs) were prepared against the Mebus strain of bovine enteric coronavirus, 14 of them reacting with the peplomeric S (gp 100) glycoprotein. Competition binding assays allowed the definition of at least 4 distinct antigenic domains for the $S$ glycoprotein, designated as $\mathrm{A}, \mathrm{B}, \mathrm{C}$, and $\mathrm{D}$; epitopes associated to neutralizing activity being located in sites A, B, and C. One MAb directed to the hemagglutinin HE (gp 140/gp 65) glycoprotein inhibited the hemagglutinating activity of the virus, but had no neutralizing activity. Comparison of Quebec enteropathogenic BCV isolates using polyclonal antiserum and MAbs directed to the $\mathrm{S}$ glycoprotein confirmed their close antigenic relationship, but also revealed the occurrence of at least three distinct antigenic subgroups. Antigenic domain D was highly conserved among $\mathrm{BCV}$ isolates, as well as non-neutralizing epitopes assigned to antigenic domains $\mathrm{A}$ and $\mathrm{C}$. The Minnesota strain of turkey enteric coronavirus could be distinguished from BCV isolates by MAbs directed to epitopes of antigenic domain $\mathrm{C}$, whereas human coronavirus $\mathrm{HCV}-\mathrm{OC} 43$ could be distinguished by MAbs directed to epitopes of antigenic domain $\mathrm{A}$. The porcine hemagglutinating encephalomyelitis virus could be distinguished from the other hemagglutinating coronaviruses by neutralizing epitopes located on antigenic domains $\mathrm{A}, \mathrm{B}$, and C.

Bovine coronavirus (BCV) is a member of the family Coronaviridae, which replicates in the differentiated enterocytes of the small and large intestines, causing severe diarrhea in newborn calves [18], winter dysentery (hemorrhagic enteritis) or chronic shedding in adult cattle $[4,21]$. The virus is also responsible 
for upper respiratory tract illness in growing calves [20]. The virion contains four major structural proteins: the $52 \mathrm{k}$ nucleocapsid $(\mathrm{N})$ protein, the $24-26 \mathrm{k}$ transmembrane or matrix (M) glycoprotein, the $180-200 \mathrm{k}$ spike (S) glycoprotein, and the 125-140 k hemagglutinin/esterase (HE) glycoprotein $[14,17]$. The $\mathrm{S}$ glycoprotein often is posttranslationally cleaved by host-cell proteases into two $100 \mathrm{k}$ fragments, $\mathrm{S} 1$ and $\mathrm{S} 2$, respectively, corresponding to the $\mathrm{N}$ - and $\mathrm{C}$ terminal subunits $[1,10]$. The HE glycoprotein is a disulphide-linked dimer of $65 \mathrm{k}$ subunits and is associated to additional small granular projections located at the base of the typical large bulbous peplomers of the hemagglutinating coronavirions $[9,10,17]$. Both $\mathrm{S}$ and $\mathrm{HE}$ interact with receptors on the cell surface $[23,24]$ and trigger the immune system eliciting the production of neutralizing antibodies $[8,11,26]$.

On the basis of serological studies, BCV has been classified in the subgroup of hemagglutinating coronaviruses, including the hemagglutinating encephalomyelitis virus of swine (HEV), the human respiratory coronavirus $\mathrm{HCV}-\mathrm{OC} 43$, the turkey coronavirus (TCV), and the various strains of mouse hepatitis virus $[8,9,25]$. These viruses all share antigenic determinants located on their homologous structural proteins [14]. Comparison of the nucleotide sequences of the structural genes and molecular hybridization studies with cDNA probes confirm this antigenic classification $[1,3,22,28,30]$. Although there exist BCV strains that can be distinguished for their pathogenicity, there is still some controversy as to the existence of distinct $\mathrm{BCV}$ serotypes. Polyclonal antisera and monoclonal antibodies (MAbs) that were raised against a BCV strain (S2) isolated in Scotland detected only minor strain variations among five cell cultureadapted strains of BCV by both indirect immunofluorescence (IIF) and hemagglutination inhibition tests (HAI) [12]. Similar findings were also reported by counterimmunoelectrophoresis and immunodiffusion tests [5]. More recently, anti-S MAbs were found to distinguish between vaccine and wild-type BCV strains in mildly denaturating Western and neutralization assays [15]. Two neutralizing epitopes appear to be conserved in virulent and avirulent strains, while two epitopes of the avirulent strains are not detected in the wildtype strains; non-neutralizing epitopes appear to be conserved among the various isolates $[12,15]$. We report here the production of MAbs against the Mebus strain of BCV and the detection of antigenic plurality among bovine coronaviruses isolated from dairy cattle in Quebec through the reaction of MAbs against the $\mathrm{S}$ glycoprotein.

The cell culture-adapted Mebus strain [18] of BCV was obtained from the American Type Culture Collection (ATCC VR 874), Rockville, MD. The prototype BCV was originally isolated in bovine fetal kidney cells from diarrhea fluid of calf [18]. Our virus strain had been passaged five times in human rectal tumour (HRT-18) cells in the presence of $10 \mathrm{U} / \mathrm{ml}$ bovine pancreatic trypsin, as previously described $[6,8]$. Twelve other $\mathrm{BCV}$ isolates were recovered from clinical cases of epidemic diarrhea in newborn calves in Quebec dairy herds from January 1987 to May 1990. No commercial BCV vaccine had been applied 
in these herds during the year preceeding these outbreaks. We received the Minnesota strain [6] of TCV from Dr. B. S. Pomeroy of the University of Minnesota, St. Paul, MN, and HCV-OC 43 [14] from Dr. P. J. Talbot, Institute Armand-Frappier, Laval, Qc, Canada. The $67 \mathrm{~N}$ strain [14] of HEV was obtained from the ATCC (VR-740). All these hemagglutinating coronaviruses were serially propagated in HRT-18 cells in the presence of trypsin $[6,8]$.

Under the following conditions, the yield of viral production after three to five successive passages was similar for the different isolates as revealed by IIF [8] or indirect immunoperoxidase [2], and calculation of the infectivity titers (ranged between $10^{5.5}$ and $10^{6.5} \mathrm{TCID} 50 / \mathrm{ml}$ ). The extracellular virions of the various $\mathrm{BCV}$ isolates were purified by differential and isopycnic ultracentrifugation on continuous 20 to $55 \%(\mathrm{v} / \mathrm{v})$ sucrose gradients, as previously described [6]. Electron microscopic examination of purified viral preparations revealed that most viral particles possessed the double fringe of surface projections [9].

Monoclonal antibodies to the Mebus strain of BCV were produced from BALB/c mice, as previously described [7]. Hybrid cells were cultured in HATmedium containing $10 \%$ fetal calf serum and $10 \%$ Boehringer Mannheimcondimed $\mathrm{H} 1$ medium (supernatant of a mouse lymphoma cell line supplemented with $1 \mathrm{mmol} / 1$ oxaloacetate, $1 \mathrm{mmol} / 1$ sodium pyruvate, $0.2 \mu \mathrm{g} / \mathrm{ml}$ insulin, $10 \mathrm{ng} /$ ml PMA, pH 7.6) in replacement of feeder layers of mouse macrophages. The supernatant from growing hybridomas was screened for anti-BCV antibody production by both IIF and ELISA. Antibody producing hybridomas were terminally diluted twice before inoculation into peritoneal cavity of pristane (2,6,10,14-tetramethylpentadecane) primed mice. Purification of immunoglobulins (IgG) from ascitic fluid, and initial characterization of MAbs and their titration by virus neutralization, ELISA, or HAI tests were also done as previously described [7].

Administration of BALB/c mice with either purified whole virus or NP 40denaturated virus prepared from the supernatant fluids of BCV-infected HRT18 cells induced high specific humoral response. Titers of serum from mice providing the immune cells ranged from 1280 to 5120 by IIF, while titers higher than 256,000 were obtained by ELISA. Of 64 hybridoma cell lines initially secreting anti-BCV MAbs, as determined by IIF and ELISA, 20 could be subcloned, serially propagated, and used to produce ascitic fluids. $\log _{10}$ ELISA titers of clarified ascitic fluids ranged from 2.9 to 6.2 .

The polypeptide specificity of the anti-BCV MAbs purified from ascitic fluids was determined by Western immunoblotting $[7,8]$. The four major proteins described previously for $\mathrm{BCV}$ isolates $[14,17]$ were identified by using homologous hyperimmune rabbit serum. Under the conditions used, 14 hybridomas produced MAbs that recognized the $\mathrm{S}$ glycoprotein. These MAbs reacted either with gp 200 or gp 100, or both protein species (data not shown). Only one hybridoma produced MAbs reacting to the HE glycoprotein. In addition, 
four MAbs reacted specifically to the $N$ protein and another reacted to the $M$ glycoprotein.

In order to correlate biological functions with polypeptide specificities, antiBCV MAbs were studied for their ability to neutralize the virus and to inhibit its hemagglutinating activity. Characterization of the isotypes of the MAbs showed that most antibodies belonged to the IgG 2A, IgG 2B or IgG 1 subclass. Neutralization studies revealed that five of the MAbs have a strong neutralizing activity (VN titers ranging between 2560 and 10240), whereas three others had a lower neutralizing activity (VN titers ranging from 160 to 640). All these MAbs were identified as anti-gp 100 MAbs by Western immunoblotting (Table 1). Six of the anti-S MAbs were devoid of neutralizing activity; they were directed either to the gp 100 or gp 200 glycoproteins. None of the MAbs to the $\mathrm{N}$ or the $\mathrm{M}$ structural proteins neutralized virus infectivity in vitro. The monoclonal BCA 3 that reacted to gp 125-140 inhibited the HA activity of the virus, but did not show neutralizing activity.

A direct relationship exists between the avidity and the maximal amount of $\mathrm{MAb}$ bound to a given amount of antigen $[13,19]$. The anti-S MAbs were titrated in an indirect ELISA and the avidities were estimated using the plateau level absorbance values; they varied between 0.80 and 1.50 (Fig. 1). At a concentration of $0.01 \mu \mathrm{g}$ of gammaglobulin per well, only MAbs BCA 2, BCF 4, BCB 5, BCB 1, and BCA 3 were able to saturate those viral antigens coated. The MAbs BCA 7, $\mathrm{BCH} 1, \mathrm{BCH} 5$, and $\mathrm{BCH} 8$ did not reach a plateau level within the range studied, thus suggesting significantly lower relative avidities for the $\mathrm{S}$ glycoprotein.

In order to determine whether the anti-S MAbs could be divided into clusters recognizing the same immunogenic region of the peplomer protein, competition immunoassays were conducted according to Deregt et al. [11]. Affinity purified antibodies were conjugated to $\mathrm{D}$-biotin $\mathrm{N}$-succinimide ester (molecular ratio $90: 1$ ) according to the method described by Kendall et al. [16]. Conjugation had no apparent adverse effect on the binding properties of ten of the purified anti-S MAbs and endpoint titers ranged from approximately $10^{4}$ to $10^{5}$. To define overlapping antibody-binding sites, competition was considered to be positive only if it occurred reciprocally and over a range of several $\log _{10}$ dilutions; each antibody was used both as competitor and biotinylated probe $[11,19]$.

The results of the competition binding experiments conducted with these ten anti-S MAbs are summarized in Table 1. By their reactivity in competition binding assays with biotinylated MAbs, anti-S MAbs fell into four competitive binding groups, A, B, C, and D, and between individual members of each group the competition was generally strong and reciprocal. An epitope map showing the main antigenic domains delineated on the BCV peplomeric $S$ glycoprotein was deduced from the competition binding experiments and is illustrated in Fig. 2. Epitopes associated with the neutralizing activity are located on sites A, $\mathrm{B}$, and $\mathrm{C}$. Antigenic domains $\mathrm{A}$ and $\mathrm{B}$ appeared to be associated with a strong neutralizing activity and were recognized by $\mathrm{MAbs} \mathrm{BCF} 4, \mathrm{BCB} 1$, and $\mathrm{BCH} 5$, 
MAbs against bovine enteric coronavirus

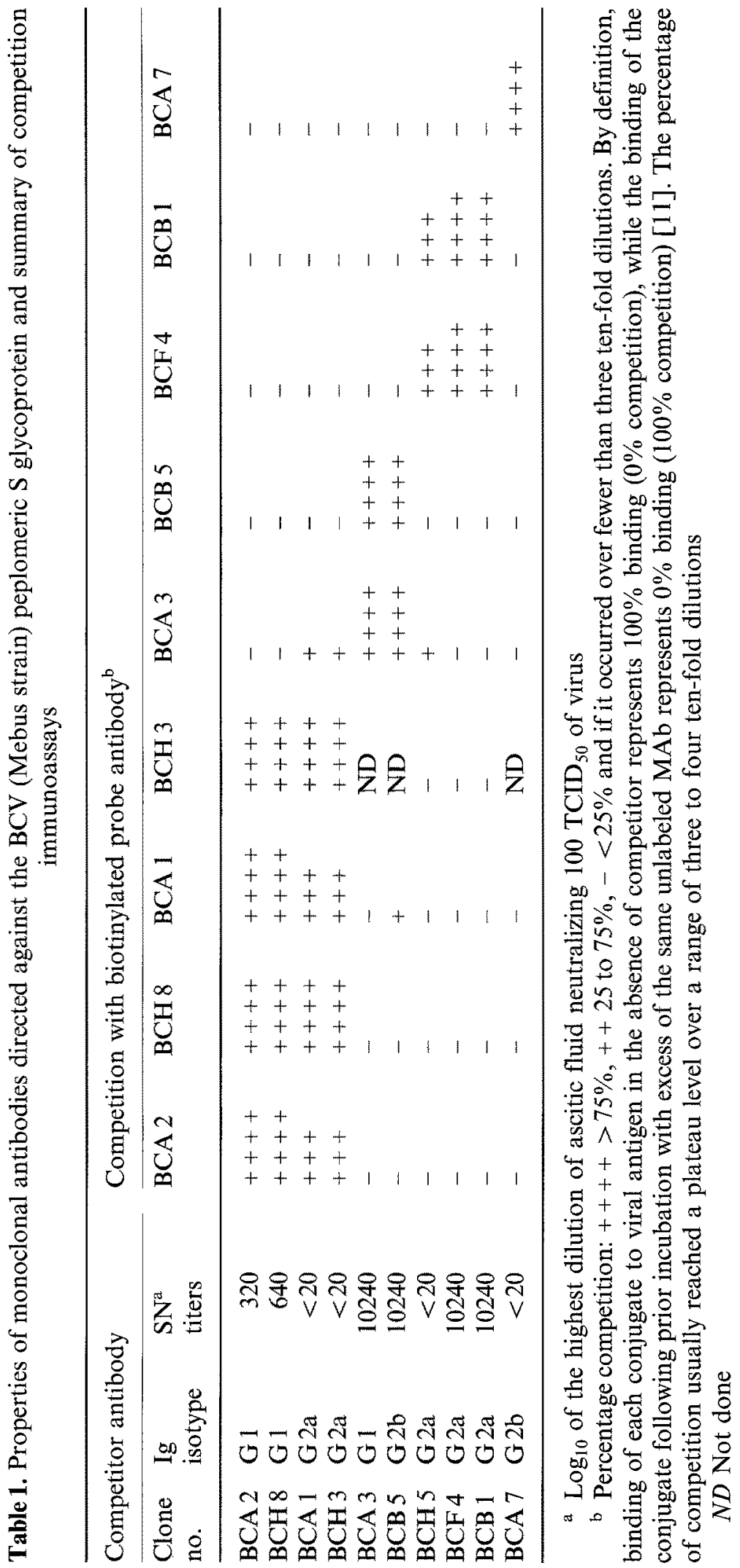



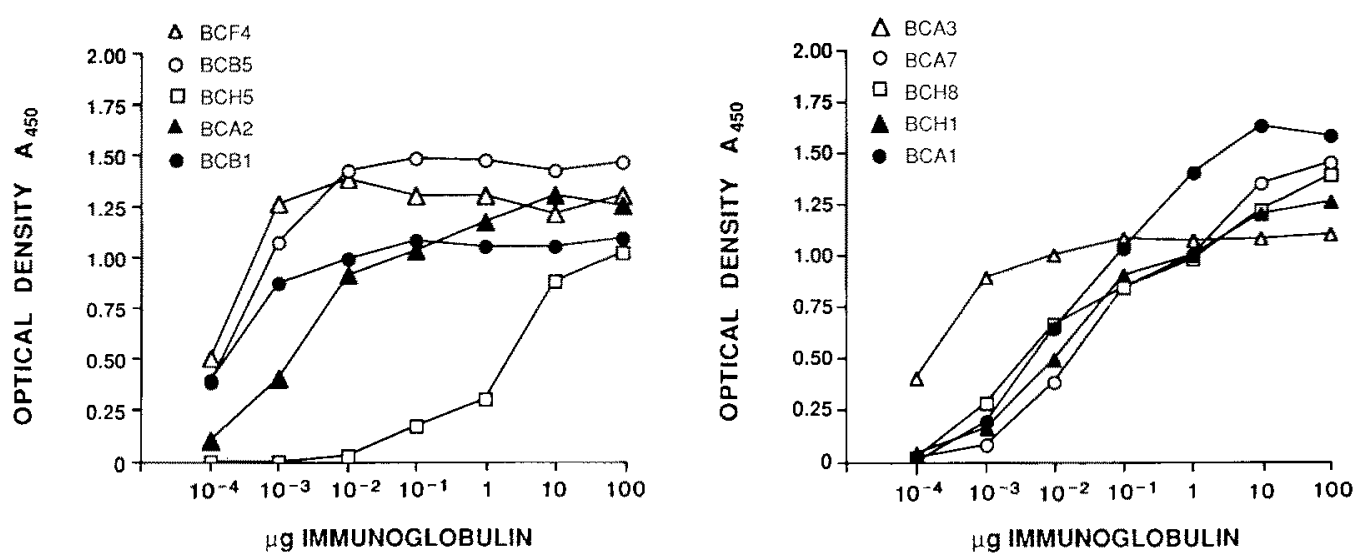

Fig. 1. Comparative avidity of monoclonal antibodies directed against the BCV (Mebus strain) peplomeric S glycoprotein. Serial ten-fold dilutions of purified antibody were incubated in the wells of microtiter plates containing absorbed purified $\mathrm{BCV}$ virions $(0.5 \mu \mathrm{g}$ of protein). After incubation for $90 \mathrm{~min}$ at $37^{\circ} \mathrm{C}$, binding to the viral antigen was detected by the addition of peroxidase-labeled goat anti-mouse IgG. The resulting A 450 value was read and used to rate MAbs for avidity

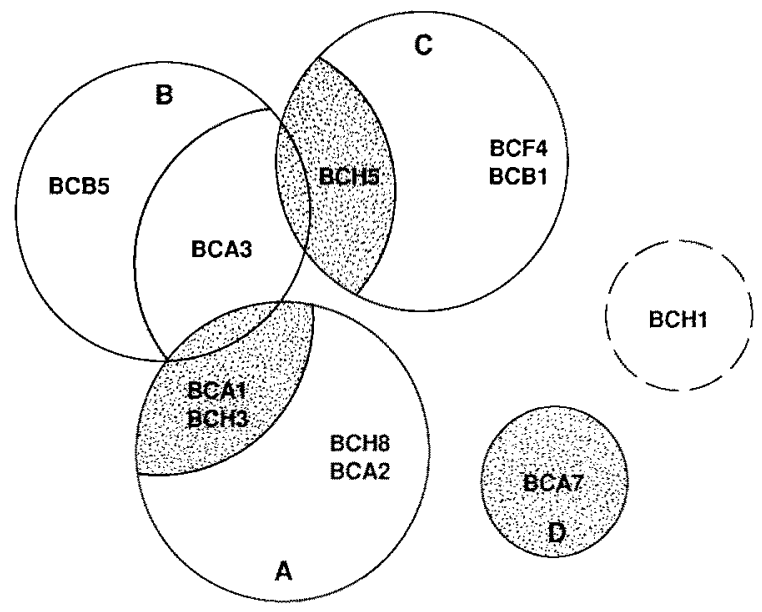

Fig. 2. Antigenic map of BCV (Mebus strain) peplomeric $\mathrm{S}$ glycoprotein deduced from competitive binding assays. $A, B, C$, and $D$ Four antigenic sites defined by the anti-S (gp 100) monoclonal antibodies. The MAbs defining each site are indicated in the corresponding circle. Antigenic site $\mathrm{B}$ is partly related to antigenic sites $\mathrm{A}$ and $\mathrm{C}$ via common non-neutralizing epitopes (shadowed). The neutralizing $\mathrm{MAb} \mathrm{BCH} 1$, an antibody of apparent low avidity, could not be assigned to a particular antigenic group since a reciprocal competition experiment could not be done due to the lack of biotinylated probe. However, the neutralizing epitope defined by this $\mathrm{MAb}$ has been found to be conserved among all $\mathrm{BCV}$ isolates analysed and for this reason was assigned to another antigenic site. The antigenic sites on the peplomeric glycoprotein of BCV were designated according to the nomenclature used by Deregt et al. [11] and Vautherot et al. [27] 
and MAbs BCB 5 and BCA 3, respectively. The anti-S MAbs having a weak neutralizing activity (BCA 2, BCH 8) or devoid of neutralizing activity (BCA 1 and $\mathrm{BCH} 3$ ) defined antigenic domain $\mathrm{C}$. The anti-S reactivity of MAbs BCA 7 could not be blocked by the other MAbs and for this reason it was suggested to be directed against a distinct non-neutralizing antigenic domain. Furthermore, antibodies $\mathrm{BCA} 1$ and $\mathrm{BCH} 3$, and $\mathrm{BCH} 5$, which were assigned to antigenic domains $\mathrm{C}$ and $\mathrm{A}$, showed reciprocal competition with monoclonal BCA 3 assigned to antigenic domain $B$. This suggests the presence of overlapping regions among major antigenic domains of the S glycoprotein that are involved in the neutralizing activity.

The BCV anti-S MAbs were tested for their cross-reactivity with other hemagglutinating coronaviruses and were applied to analyse bovine coronaviruses isolated from dairy cattle in Quebec. In preliminary experiments using polyclonal rabbit antisera, the relationship among HCV-OC 43, HEV, TCV, and $\mathrm{BCV}$ was confirmed by IIF and Western immunoblotting; by HAI and neutralization assays, only TCV and BCV appeared to be serologically related [8]. Furthermore, using polyclonal antisera, there was no evidence from this study to warrant distinction of the various Quebec BCV isolates into classical serotypes (data not shown).

The cross-reactivity of BCV anti-S MAbs was tested in an indirect ELISA [7]. Twice the amount of MAb giving maximal binding to the Mebus strain of $\mathrm{BCV}$ was used for antigenic comparison. As illustrated in Fig. 3, binding to the heterologous virus strains was expressed as a percentage of the absorbance values obtained with the reference virus. Overall, at least three antigenic groups could be recognized among the BCV isolates studied. Two Quebec isolates of BCV (BCQ 4 and BCQ 718) reacted similarly to the Mebus strain with the 12 MAbs tested. The MAbs $\mathrm{BCH} 6, \mathrm{BCH} 1$, and $\mathrm{BCA} 7$ did not show significant variability among the various Quebec $\mathrm{BCV}$ isolates, and bound intensively to the three other hemagglutinating coronaviruses tested. The MAbs BCB 1, $\mathrm{BCF} 4, \mathrm{BCB} 5$, and $\mathrm{BCA} 3$ reacted with a very low intensity against eight of the Quebec isolates. Among the latter, six reacted strongly with the other MAbs. The BCV isolates BCQ9, BCQ 12, and BCQ 2070, and HEV exhibited no reactivity to the four previous MAbs and to $\mathrm{MAbs} \mathrm{BCH} 3, \mathrm{BCA} 1, \mathrm{BCH} 8$, and $\mathrm{BCA} 2$. Four of the anti-BCV MAbs (BCH 5, BCB 1, BCF 4, and $\mathrm{BCH} 3)$ did not react against $\mathrm{HCV}-\mathrm{OC} 43$. The Minnesota strain of TCV reacted strongly with most of the anti-BCV MAbs; this virus appeared to differ from the reference $\mathrm{BCV}$ strain only by its lower reactivity to $\mathrm{MAbs} \mathrm{BCH} 3, \mathrm{BCH} 8$, and $\mathrm{BCA} 2$ ( $50 \%$ of the value obtained with the homologous virus).

In the present study, data obtained in the competition binding experiments with $\mathrm{BCV}$ anti-S MAbs were in agreement with previous findings reported in cases of an avirulent $(B C Q 2)$ and a virulent $\left(G_{110}\right) B C V$ strain $[11,26]$. However, a more extensive MAb library is required to establish more definitive spacial and operational mapping of the antigenic determinants carried by the $\mathrm{S}$ glycoprotein of the BCV virion. Vautherot et al. [27] have identified a total of 

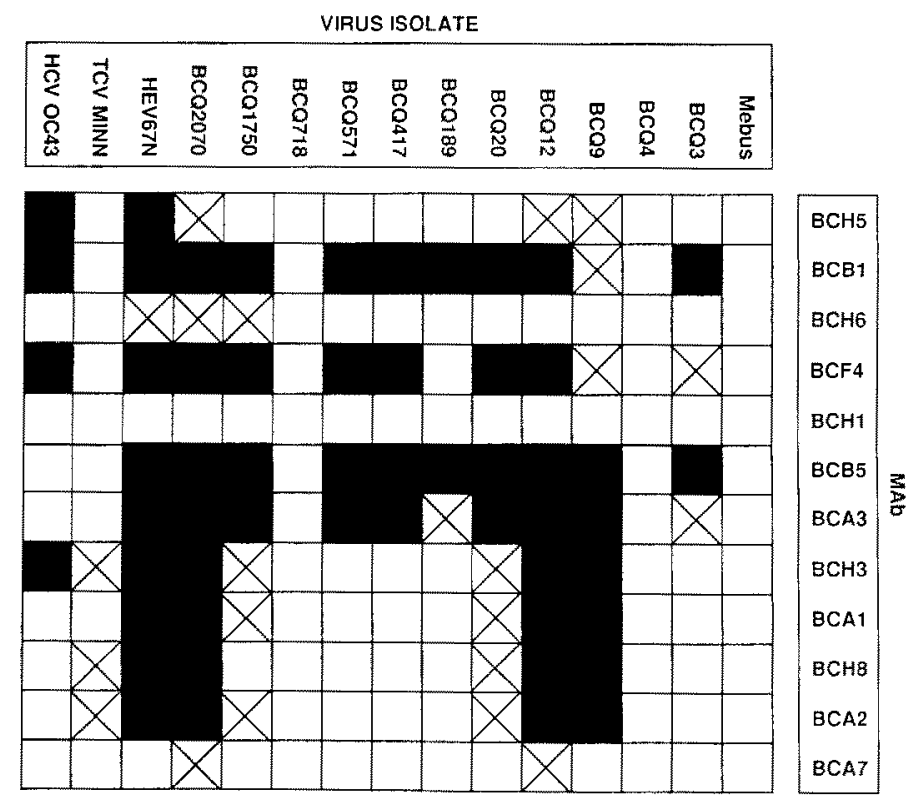

Fig. 3. Cross-reactivity of monoclonal antibodies to the $\mathrm{S}$ glycoprotein of the Mebus strain of $\mathrm{BCV}$ with Quebec BCV isolates. The cross-reactivity between the various isolates was tested by an indirect ELISA. Twice the amount of MAb giving maximal binding to the Mebus strain was used. Binding to the heterologous virus is expressed as a percentage of the $A_{450}$ value obtained with the homologous virus. $\square 50$ to $100 \%$; $\square 25$ to $50 \%$; $\square$ less than $25 \%$

seven antigenic domains for the $\mathrm{S}$ glycoprotein of $\mathrm{BCV}$ by means of a competitive binding assay; four independent antigenic domains were found to be located on $\mathrm{S} 1$, two on $\mathrm{S} 2$, and one on gp 200. As demonstrated in the present study, most of the neutralizing-mediating determinants appeared to cluster in two major antigenic domains of the $\mathrm{S} 1$ subunit, $\mathrm{A}$ and $\mathrm{B}$, the latter being subdivised into subsites [27]. Recently, BCV anti-S MAbs BCB 5, BCA 3, BCF 4, and $\mathrm{BCB} 1$ that possess a strong neutralizing activity were found to react against the spike glycoprotein $\mathrm{S} 1$ subunit, expressed by recombinant baculovirus [29; Parker M.D., pers. comm.].

Comparison of Quebec enteropathogenic BCV isolates using polyclonal antisera and $\mathrm{MAbs}$ directed to the $\mathrm{S}$ glycoprotein confirmed their close antigenic relationship, but also revealed the occurrence of at least three distinct antigenic subgroups. These subgroups were identified by neutralizing MAbs directed to epitopes of antigenic domains $A, B$, and $C$. Antigenic domain $D$ of the $S$ glycoprotein, defined by MAb BCA 7, appeared to be highly conserved among Quebec BCV isolates, as well as a non-neutralizing epitope assigned to antigenic domain A. Three Quebec BCV isolates differed from the other by neutralizing and non-neutralizing epitopes assigned to antigenic domain $\mathrm{C}$. Another neutralizing $\mathrm{MAb}(\mathrm{BCH} 1)$, that could not be assigned to the aforementioned antigenic domains, was found to be directed to an epitope highly preserved 
among the various $\mathrm{BCV}$ isolates, as well as the three other hemagglutinating coronaviruses tested. The Minnesota strain of TCV, which could not be differentiated from $\mathrm{BCV}$ by virus neutralization tests using polyclonal rabbit or turkey hyperimmune sera [8], was found to differ from the latter by epitopes of antigenic domain $\mathrm{C}$. These epitopes appeared to be associated with weak neutralizing activity. Epitopes of antigenic domains A and B, associated to a strong neutralizing activity, appeared to be highly conserved among both viruses, thus confirming previous reports on the close antigenic and genomic relationship between the turkey and bovine enteropathogenic coronaviruses $[8,9,28]$.

On the other hand, the HCV-OC 43 could be distinguished by neutralizing MAbs directed to epitopes of antigenic domain A. These results are in agreement with previous findings showing that non-neutralizing anti-gp 200 MAbs map a unique site located on the $\mathrm{S} 2$ part of the peplomer glycoprotein and react similarly with various hemagglutinating coronaviruses, whereas anti-gp 105 MAbs, that defined at least four independent neutralizing or non-neutralizing domains on the S1 part of the peplomer glycoprotein, react only with the homologous virus [26]. Using polyclonal hyperimmune sera, we were unable to show cross-reactivity by virus neutralization between the human and bovine hemagglutinating coronaviruses, but common epitopes located on their various structural proteins were recognized by Western immunoblotting [14]. Recently, high degrees of homology were demonstrated for the nucleotide sequence of the $\mathrm{S}$ and $\mathrm{HE}$ genes of both viruses [31].

The porcine hemagglutinating encephalomyelitis virus could be distinguished from the other hemagglutinating coronaviruses tested by neutralizing epitopes located on antigenic domains A, B, and C. These results are also in agreement with those obtained by Vautherot et al. [26] who have demonstrated that HEV can be differentiated from the other hemagglutinating coronaviruses by its reactivity to epitopes located on the various antigenic domains of the $\mathrm{S} 1$ part of the peplomer glycoprotein.

Recently, comparison of the S gene sequences of six highly virulent or avirulent BCV isolates have revealed more than $98 \%$ homologies in spite of different origins of the viruses $[15,31]$. Overall, there were only 45 to 56 nucleotide differences between the virulent and avirulent groups, while there were 6 to 14 differences among four avirulent strains. It has been speculated that substitutions of few amino acids in the putative fusogenic domains and two proline at position 507 and 567 in the antigenic domains may cause altered immunogenic and other functional properties of the $S$ proteins specified by the virulent and avirulent BCV strains [31]. Nucleotide sequence analysis of the portion of the $\mathrm{S} 1$ gene corresponding to the two major neutralizing domains are presently in progress in order to establish the significance of the differences observed among the Quebec BCV isolates.

\section{Acknowledgements}

The authors thank Nicole Sawyer for technical assistance. We would also like to acknowledge the help of Dr M. D. Parker, VIDO, Saskatoon, Saskatchewan, for testing the spec- 
ificity of anti-S MAbs to the spike glycoprotein $\mathbf{S} 1$ subunit expressed by recombinant baculovirus. This research was supported in part by grants received from the National Research Council of Canada and the Fonds pour la Formation de Chercheurs et l'Aide à la Recherche du Quebec.

\section{References}

1. Abraham S, Kienzle TE, Lapps W, Brian DA (1991) Deduced sequence of the bovine coronavirus spike protein and identification of the internal proteolytic cleavage site. Virology 176: 296-301

2. Belanger F, Alain R, Payment P, Lecomte J, Trudel M (1988) Rapid titration of bovine, caprine and human RS virus by a micro-immunoperoxidase assay using a monoclonal antibody and a permissive porcine kidney cell line. J Virol Methods 20: 101-107

3. Boireau P, Cruciere C, Laporte J (1990) Nucleotide sequence of the glycoprotein S gene of bovine enteric coronavirus and comparison with the $\mathrm{S}$ proteins of two mouse hepatitis virus strains. J Gen Virol 71: 487-492

4. Crouch CF, Bielefeldt-Ohmann H, Watts TC, Babiuk LA (1985) Chronic shedding of bovine enteric coronavirus antigen antibody complexes by clinically normal cows. $J$ Gen Virol 66: 1489-1500

5. Dea S, Roy RS, Elazhary MASY (1982) Antigenic variations among calf diarrhoea coronaviruses by immunodiffusion and counterimmuno-electrophoresis. Ann Rech Vet 13: $351-356$

6. Dea S, Garzon S, Tijssen P (1989) Isolation and trypsin-enhanced propagation of turkey enteric (bluecomb) coronaviruses in a continuous human rectal adenocarcinoma cell line. Am J Vet Rec 50: 1310-1318

7. Dea S, Tijssen P (1989) Antigenic and polypeptide structure of turkey enteric coronaviruses as defined by monoclonal antibodies. J Gen Virol 70: 1725-1741

8. Dea S, Verbeek AJ, Tijssen P (1990) Antigenic and genomic relationships among turkey and bovine enteric coronaviruses. J Virol 64: 3112-3118

9. Dea S, Garzon S (1991) Identification of coronaviruses by the use of indirect protein A-gold immunoelectron microscopy. J Vet Diagn Invest 3: 297-305

10. Deregt D, Sabara M, Babiuk LA (1988) Structural proteins of bovine coronavirus and their intracellular processing. J Gen Virol 68: 2863-2877

11. Deregt D, Babiuk LA (1987) Monoclonal antibodies to bovine coronavirus: characteristics and topographical mapping of neutralizing epitopes on the E 2 and E 3 glycoproteins. Virology 161: 410-420

12. El-Ghorr AA, Snodgrass DR, Scott FMM, Campbell I (1989) A serological comparison of bovine coronavirus strains. Arch Virol 104: 241-248

13. Frankel ME, Gerhard W (1979) The rapid determination of binding constants for antiviral antibodies by a radio-immunoassay. An analysis of the interaction between hybridoma proteins and influenza virus. Mol Immunol 16: 101-106

14. Hogue BG, King B, Brian DA (1984) Antigenic relationships among proteins of bovine coronavirus, human respiratory coronavirus OC 43 , and mouse hepatitis coronavirus A 59. J Virol 51: $384-388$

15. Hussain KA, Storz J, Kousoulas KG (1991) Comparison of bovine coronavirus (BCV) antigens: monoclonal antibodies to the spike protein distinguish between vaccine and wild-type strains. Virology 183: 442-445

16. Kendall C, Ionescu-Matiu I, Dreesman GR (1983) Utilization of the biotine/avidin system to amplify the sensitivity of the enzyme-linked immunosorbent assay (ELISA). J Immunol Methods 56: 329-339

17. King B, Potts BJ, Brian DA (1985) Bovine coronavirus hemagglutinin protein. Virus Res 2: 53-59 
18. Mebus CA, Stair EL, Rhodes MB, Twiehaus MJ (1973) Neonatal calf diarrhoea: propagation, attenuation, and characteristics of a coronavirus-like agent. Am J Vet Res 34: 145-150

19. Niesters HGM, Bleumink-Pluym NMC, Osterhaus ADME, Horzinek MC, Van Der Zeijst BAM (1987) Epitopes on the peplomer protein of infectious bronchitis virus strain M41 as defined by monoclonal antibodies. Virology 161: 511-519

20. Reynolds DJ, Debney TG, Hall GA, Thomas LH, Parsons KR (1985) Studies on the relationship between coronaviruses from the intestinal and respiratory tracts of calves. Arch Virol 85: 71-83

21. Saif LJ, Brock KV, Redman DR, Kohler EM (1991) Winter dysentery in dairy herds: electron microscopic and serological evidence for an association with coronavirus infection. Vet Rec 128: 447-449

22. Shockley LJ, Kapke PA, Lapps W, Brian DA, Potgiever LNW, Woods Rh (1987) Diagnosis of porcine and bovine enteric coronavirus infections using cloned cDNA probes. J Clin Microbiol 25: 1591-1596

23. Schultze B, Wahn K, Klenk HD, Herrler G (1991) Isolated HE protein from hemagglutinating encephalomyelitis virus and bovine coronavirus has receptor-destroying and receptor-binding activity. Virology 180: 221-228

24. Schultze B, Gross HJ, Brossmer R, Herrler G (1991) The S protein of bovine coronavirus is a hemagglutinin recognizing $9-O$-acetylated sialic acid as a receptor determinant. $\mathrm{J}$ Virol 65: 6232-6237

25. Siddell S, Wege H, Ter Meulen V (1983) The biology of coronaviruses. J Gen Virol 64: $761-776$

26. Vautherot JF, Laporte J, Madelaine MF, Bobulesco P, Roseto A (1984) Antigenic and polypeptide structure of bovine enteric coronavirus as defined by monoclonal antibodies. Adv Exp Med Biol 173: 117-132

27. Vautherot JF, Madelaine MF, Boireau P, Laporte J (1992) Bovine coronavirus peplomer glycoproteins: detailed antigenic analysis of S 1, S 2, and HE. J Gen Virol 73: $1725-1737$

28. Verbeek A, Tijssen P (1991) Sequence analysis of the turkey enteric coronavirus nucleocapsid and membrane protein genes: a close genomic relationship with bovine coronavirus. J Gen Virol 72: 1659-1666

29. Yoo D, Parker MD, Song J, Cox GJ, Deregt D, Babiuk LA (1991) Structural analysis of the conformational domains involved in neutralization of bovine coronavirus using deletion mutants of the spike glycoprotein $\mathrm{S} 1$ subunit expressed by recombinant baculoviruses. Virology 183: 91-98

30. Zhang X, Kousoulas KG, Storz J (1992) The hemagglutinin/esterase gene of human coronavirus strain $\mathrm{OC} 43$ : phylogenetic relationships to bovine and murine coronaviruses and influenza $C$ virus. Virology 186: 318-323

31. Zhang X, Kousoulas KG, Storz J (1991) Comparison of the nucleotide and deduced amino acid sequences of the $S$ genes specified by virulent and avirulent strains of bovine coronaviruses. Virology 183: 397-404

Authors' address: Dr. S. Dea, Centre de Recherche en Virologie, Institut ArmandFrappier, 531 boulevard des Prairies, Laval-des-Rapides, Québec H7V 1B7, Canada.

Received October 8, 1992 